\title{
Социальная культура тувинцев и онлайн-пространство
}

\author{
Чимиза К. Ламажаа \\ Тувинский государственный университет; Тувинский институт гуманитарных и прикладных \\ социально-экономических исследований при Правительстве Республики Тыва, Российская Федерация
}

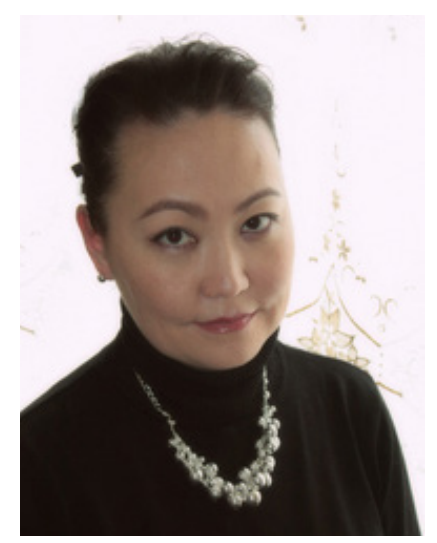

В статье анализируется проблема: как современные технологии стали для тувинцев, помимо всего прочего, своеобразными проводниками архаизации - процесса возвращения к архаическим социальным и культурным связям и смыслам. Источником данных являются результаты авторского опроса тувинцев, пользующихся социальными сетями, мессенджерами. Опрос состоялся в начале 2021 г. методом случайной выборки, охватил 205 человек, ответивших на вопросы анкеты в Google Forms.

Российская киберэтнография сегодня больще сконцентрирована на изучении презентации этничности в Интернете. Автор предлагает пойти дальше и рассмотреть сеть как новое пространство для функционирования социальной культуры этноса на примере тувинцев. В основе анализа - идеи антропологов К. Хайн и Г. Рейнгольда, что позволяет говорить о сетевой социальности как факте социальной реальности.

Развитие беспроводного Интернета в Туве привело к тем же результатам, что и во всем мире - люди научились действовать совместно в условиях, которые ранее этого не допускали. Значительное число тувинцев имеют группы (родственников, коллег, друзей) в мессенджерах, прежде всего Viber, общение в которых имеет различные социальные «последствия». Чаще всего Viber используется для связи со знакомыми, родственниками (90,2\%). Родственные группы насчитывают от 13 до 70 человек, общение в них ведется почти постоянно, чаще всего на тувинском языке; участники обмениваются информацией, новостями и договариваются о совместных действиях. Использование интернеткоммуникаций как возможность сплочения, координации действий позволяет тувинцам максимально результативно участвовать в голосованиях в интернет-конкурсах разного масштаба.

Исторический экскурс позволяет увидеть, что пространство социальной культуры тувинцев подвергалась на протяжении истории изменениям, а социальная культура сохранила свои основные ценности - значимость социальных связей родственных групп.

Ключевые слова: тувинцы; Тува; социальная культура; пространство; понимание пространства; картина мира; социальная сеть; мессенджер; родственная группа

Подготовлено при финансовой поддержке Российского научного фонда в рамках научного проекта «Тезаурус этнической культуры в XXI веке: проблемы исследования и сохранения (на примере тувинской культуры)» (грант № 21-18-00246).

Для цитирования:

Ламажаа Ч. К. Социальная культура тувинцев и онлайн-пространство // Новые исследования Тувы. 2021, № 2. C. 115-129. DOI: https://www.doi.org/10.25178/nit.2021.2.10

Ламажаа Чимиза Кудер-ооловна - доктор философских наук, заведующая лабораторией этнологии и лингвокультурологии Тувинского государственного университета; главный научный сотрудник отдела религиоведения и культурологии Тувинского института гуманитарных и прикладных социально-экономических исследований при Правительстве Республики Тыва. Адрес: 667000, Россия, г. Кызыл, ул. Ленина, д. 36; 667000, Россия, г. Кызыл, ул. Кочетова, д. 4 . Тел.: +7 (916) 413-33-85. Эл. адрес: lamazhaa@tuva.asia

LAMAZHAA, Chimiza Kuder-oolovna, Doctor of Philosophy, Head, Laboratory of Ethnology and Linguoculturology, Tuvan State University; Chief Researcher, Department of Religious Studies and Cultural Studies, Tuvan Institute of Humanities and Applied Social and Economic Research under the Government of Tuva. Postal address: 36 Lenina St., 667000 Kyzyl, Russia; 4 Kochetova St., 667000 Kyzyl, Russian Federation. Tel.: +7 (916) 413-33-85. E-mail: lamazhaa@tuva.asia 


\title{
Social Culture of Tuvans and Online Space
}

\author{
Chimiza K. Lamazhaa \\ Tuvan State University; Tuvan Institute of Humanities and Applied Social and Economic Research, \\ Russian Federation,
}

\begin{abstract}
The article analyzes the issue of how modern technologies have become, among other things, a sort of vehicles of archaization for Tuvans, i.e. of the process of returning to archaic social and cultural ties and meanings. The source of the data is the author's survey of Tuvans who use social networks and messaging apps. The survey was conducted in early 2021 by random sampling, covering 205 people who answered the questionnaire published on Google Forms.

Today Russian cyberethnography is more focused on studying the presentation of ethnicity on the Internet. The author suggests going further and considering the network as a new space for the functioning of an ethnic group's social culture in the case of Tuvans. The analysis is based on the ideas of the anthropologists Ch. Hine and H. Rheingold. This allows us to talk about a network sociality as a fact of social reality.

The development of wireless Internet in Tuva has led to the same results as all over the globe - people have learned to act together in conditions that previously did not permit this. A significant number of Tuvans use chat groups (of relatives, colleagues, friends) in messaging apps, especially on Viber. Communication via them has various social "consequences". Most often, Viber is used to communicate with friends and relatives (90.2\%). The groups of relatives number from 13 to 70 people, communication in them is flowing almost constantly, typically in the Tuvan language; participants exchange information, news, and arrange collective actions. The use of web communications as a tool for unity and coordination of actions allows Tuvans to vote in online contests of various kinds as effectively as possible.

A historical insight allows us to see that the space of the social culture of Tuvans has undergone changes throughout history, and the social culture has preserved its basic values - the significance of social ties among kin groups.
\end{abstract}

Keywords: Tuvans; Tuva; social culture; space; understanding of space; worldview; social network; messaging app; kin group

\section{Financing}

The article was prepared with financial support from the Russian Science Foundation within the framework of the research project "Thesaurus of Ethnic Culture in the 21st Century: Problems of Study and Preservation (The Case of Tuvan Culture)" (grant No. 21-18-00246).

\section{Введение}

Не будет большим преувеличением сказать, что сегодня каждое утро большинства тувинцев начинается с приветствий с многочисленными родственниками и земляками. Причем вне зависимости от того, где они находятся: в столице Тувы Кызыле, в отдаленном селе, за пределами Тувы и даже России... Едва проснувшись, они обмениваются с помощью гаджетов с мобильным Интернетом пожеланиями доброго утра, свежими новостями, фотографиями. Собеседники сразу узнают о том, кто что делает в данный момент, что происходило у каждого накануне вечером и какие шалости вытворяет детвора. Они договариваются о встречах и совместных делах. Кому-то это нравится, кто-то удивляется тому, какие изменения произошли в жизни, кто-то раздражается от обилия сообщений. Можно говорить о том, какими модернизированными стали люди, какими современными стали тувинцы, как глубоко проникла глобализация и в этот когда-то закрытый край... Но эта ситуация доступности друг друга, нивелирования пространства между собеседниками каждый раз заставляет меня вспоминать архаические фольклорные сюжеты с путешествиями эпических героев, когда они преодолевают все 
препятствия, «сжимая» пространственно-временные координаты до стремительно меняющихся ощущений: «зиму узнавал по снегу, лето - по росе». Мы вроде бы с помощью технических новшеств идем в ногу с прогрессом. Но, с другой стороны, в нашу жизнь вернулось нечто старое - наши родственные связи, не зависящие от каких-либо внешних обстоятельств, пространства и времени.

Тема общего между архаическими традициями и сверхсовременными скоростями человеческих реакций, которые передают информационные коммуникации, уже заинтересовала исследователей. Так, А. В. Головнев после экспедиции к оленеводам Кольского полуострова в 2018 г. выложил в Интернет смонтированный видеоролик эпизодов вращения оленьего стада, записанных с помощью парящего над ними коптера (Головнев, 2019). Последовавшая за этим бурная реакция завороженных зрелищем зрителей из самых разных стран, которую он назвал «бурлением Сети», ему показалась весьма интересной. Речь не шла о трактовке кругового хождения самих оленей, поскольку для зоологов это может объясняться инстинктивным желанием стада защититься от хищников. Интерес был именно к реакции людей, и он побудил ученого обратиться к анализу пространственного кружения, который А. В. Головнев расценил как универсальный прием физического и ментального охвата пространства. Людей не просто привлекла визуальная красота кругового движения огромных стад, синхронность действий, но включился некий универсальный механизм, заложенный в самой природе человеческого мышления и деятельности и увлекающий на подсознательном уровне. Движение в круге ученый назвал важным базовым влечением человека, который инстинктивно стремится к природной мим-адаптации (там же: 117).

В данной работе мне хотелось бы рассмотреть на ином примере, как современные технологии не просто изменили нашу жизнь, но и стали проводниками архаизации - процесса возвращения к архаическим социальным и культурным связям и смыслам (Ламажаа, 2012). Поэтому я обращусь к анализу проблематики социальной культуры, трактуя ее как культурно обусловленные социальные нормы, социальные ценности, социальные связи. Функционирование норм, поддержание связей происходит не только в определенном социальном окружении, но, помимо этого, как мы сейчас видим, и в разных пространственных измерениях, формах - не только офлайн, но и онлайн. Но если сейчас появление онлайн-пространства для социальной культуры может считаться абсолютно новым, значит ли это, что и социальная культура также обновляется? Могут ли особенности культуры влиять на характер интернет-коммуникаций?

Для анализа нынешней ситуации, который предлагаю производить как исследование в русле антропологии современности, я опираюсь на данные моего опроса тувинцев, пользующихся социальными сетями, мессенджерами. Этот опрос состоялся в январе 2021 г. методом случайной выборки (приглашение для участия в опросе распространялось в тувинских группах в социальных сетях и мессенджерах), охватил 205 человек, ответивших на вопросы анкеты в Google Forms.

\section{Антропология современности и Интернет как пространство социальной культуры}

Распространение в последние годы в Рунете этнически ориентированных сообщений, сведений, определенных групп, чатов и пр., то есть появление национального Интернета, как пишут исследователи (Мартьянов, Мартьянова, 2012; Габдрахманова, Махмутов, 2018), привело к признанию того факта, что этничность приобрела особую виртуальную форму. Под словом «виртуальная» не подразумевается какая-то эфемерная, нереальная форма, нет: «воображением в киберпространстве создается вполне “реальная реальность” (Головнев, Белоруссова, Киссер, 2018: 100).

Это вызывает необходимость менять исследовательские подходы (Головнев, Белоруссова, Киссер, 2018; Белоруссова, Головнев, 2019). Как ранее рассуждала американо-датская исследовательница теории информации А. Маркхэм, традиционные методы этнографии здесь уже не помогают, значит надо критически изучить саму ситуацию, в которой оказался исследователь (Markham, 2013: 436). Более того, даже сами виртуальные миры, считает американский антрополог Дж. Маркус, «теперь доступны как “реальная” жизнь для полного этнографического исследования так, как этого не было раньше» (Marcus, 2012: XVIII). Поэтому онлайн-игры, анонимные форумы и пр. уже два десятилетия изучаются западными исследователями как объекты виртуальной этнографии - интерпретативной этнографии (Ethnography and virtual ..., 2012) - отрасли, в поле внимания которой входят общекультурные феномены безотносительно этнокультурной проблематики. 
В российской науке пока виртуальная этнография только начала развиваться. Санкт-петербургскими учеными она названа веб-этнографией или кибер-этнографией (А. В. Головнев, С. Ю. Белоруссова и др.) $)^{1}$ Однако, в отличие от подхода западной науки (рассматривающей этнографию прежде всего как метод), главным объектом ее остается этничность (см.: Головнев, 2018) и ее различные проявления в виртуальности. В числе недавних интересных работ, посвященных конкретным этносам, можно назвать исследования виртуальных татарских сообществ в социальной сети «ВКонтакте» (Махмутов, Габдрахманова, 2016), визуальных образов культуры кольских саамов в этой же социальной сети (Сулейманова, 2020), аспектов виртуальной идентичности российских немцев (Киссер, 2019) и др.; обзор подобных исследований также есть в работе Г. Ф. Габдрахмановой и 3. А. Махмутова (Габдрахманова, Махмутов, 2018).

В целом, на мой взгляд, российская наука находится пока больше на начальном этапе изучения этнических особенностей цифровой среды, который одна из первых западных исследователей виртуальной этнографии К. Хайн назвала условно первопроходческим. Он подразумевает изучение игры идентичностей и распределения между онлайн и офлайн-идентичностями. Второй этап (легитимизированный) включает в себя исследования офлайн-методов в онлайн-сфере, а третий (мультимодальные подходы) - сочетает различные способы коммуникаций․

Учитывая расширяющиеся возможности, которые обсуждаются западными коллегами и к которым, очевидно, придут и российские авторы, я добавлю к нашему дискурсу тему Интернета как нового пространства для функционирования социальной культуры этноса на примере тувинцев. То есть сохраняя в качестве объекта внимания этническую сторону виртуальной жизни, тем не менее, я полагаю интересным использовать идеи западной виртуальной или цифровой этнографии и смотреть на виртуальность как на новое пространство для разворачивания этносоциальных, этнокультурных процессов. Обращу внимание на идеи К. Хайн, которая предложила рассматривать Интернет как пространство социального взаимодействия, а не как простой инструмент, средство связи (Нine, 2000) и Г. Рейнольдса, сформулировавшего идею нового феномена - социальной самоорганизации с помощью высоких технологий (Rheingold, 2002). Мы можем говорить о сетевой социальности как факте социальной реальности.

При этом для анализа новой социальной реальности тувинской социокультурной жизни я ориентируюсь на идеи антропологии современности (как один из разделов социальной антропологии, обращенный непосредственно к сегодняшней реальности). По мнению А. Маркхэм, направление с таким названием «требует внимания к движению, течению и процессу, к намеренной попытке отойти от размышлений о поле как об объекте, месте или целостности» ${ }^{3}$. Главное, на мой взгляд, в исследовании антропологии современности, что «разделение онлайн и офлайн теперь не так важно, как взаимодействие между людьми, чьи жизни связаны или затронуты этими сетями» ${ }^{4}$ Но при этом, как подчеркивает А. В. Головнев, поскольку «российская традиция не противопоставляет, а сопоставляет “народ” и “человека” ...», «антропологический мотив человек не теснит этнографический мотив народа» (Головнев, 2018: 17).

\section{Новая форма связи тувинцев с родственниками сегодня}

Развитие беспроводного Интернета в Туве ${ }^{5}$ привело к тем же результатам, что и во всем мире. Как писал Г. Рейнгольд, первые признаки меняющейся социальной реальности он осознал в 2000 г., когда

\footnotetext{
${ }^{1}$ В частности, их работы, а также статьи других авторов, недавно составили материалы специальной темы «Виртуальная этничность и киберэтнография» журнала «Сибирские исторические исследования» (№ 22019 г.: http://journals.tsu.ru/siberia/\&journal_page=archive\&id=1855).

${ }^{2}$ Christine Hine on virtual ethnography’s E3 Internet [Электронный pecypc] // Ethnography matters. 2013, November 29. URL: https://ethnographymatters.net/blog/2013/11/29/christine-hine-on-virtual-ethnographys-e3-internet/ (дата обращения: 20.03.2021).

${ }^{3}$ Этнография в цифровую эпоху: от полей к потокам, от описаний к воздействию. Часть I [Электронный ресурс] // Системный Блокъ. 2019, 17 мая. URL: https://sysblok.ru/society/ethnography-in-the-digital-internet-era-1/ (дата обращения: 20.03.2021).

${ }^{4}$ Этнография в цифровую эпоху. Часть II: интернет как способ существования и Big Data как угроза [Электронный ресурс] // Системный Блокъ. 2019, 24 мая. URL: https://sysblok.ru/society/ethnography-in-the-digital-internetera-2/ (дата обращения: 20.03.2021).

${ }^{5}$ В 2012 г. в структуре правительства региона появилось новое министерство - министерство информатизации и связи. Одной из задач ведомства стало обеспечение потребности населения, а также органов власти и
} 
на улицах Токио заметил людей, не вслушивающихся в мобильные телефоны, а всматривающихся (Рейнгольд, 2006: 7). Обмен сообщениями, установление между ними связей, объединений по интересам стали повседневной реальностью. И технические средства, позволявшие все это делать, превратились «в нательные дистанционно управляемые устройства физического мира» (там же: 8). Люди научились действовать совместно в условиях, которые ранее этого не допускали (там же: 15).

Это наблюдение побудило автора дать название явлению социальной самоорганизации с помощью высоких технологий - «умная толпа» (smart mob), что и было вынесено в название монографии (оригинальное издание на английским языке: Rheingold, 2002). В российской науке его труды интересуют пока социологов, политологов, специалистов в области СМИ (Абрамов, 2006; Смирнов, 2008; Быльева, Лобатюк, 2017; Васильев, Коркия, Мамедов, 2019; и др.). А вот жизнь народов, этносоциальные процессы пока не увязывались с его идеями.

Летом 2019 г. в Тес-Хемском районе Тувы я приняла участие в обряде дагылга родственной группы со стороны мамы (Ламажаа, 2021). Обсуждение организации обряда началось за несколько месяцев в мессенджере Viber, в которой у нас есть группа для родственников. Мои расспросы земляков из самых разных районов республики показали, что и они имеют подобные группы в мессенджеры. И общение в этих группах также имеет различные социальные «последствия».

Чтобы охватить и обобщить типическое в этом явлении, в январе 2021 г. я сформулировала анкету с рядом вопросов о том, какими социальными сетями и мессенджерами пользуются тувинцы и для чего. Вопросы анкеты были перенесены в Google Forms, и информация об этом опросе была распространена через мессенджеры, сообщества в социальных сетях, в которых присутствовали тувинцы, в основном интеллигенция, т. е. опрос проходил методом «снежного кома». В итоге он охватил 205 человек.

Основные сведения респондентов ${ }^{1}$ говорят нам о том, что мы получили сведения от тувинцев, в основном, среднего возраста, работающих, представителей интеллигенции, проживающих в самых разных местах, с опытом миграции (внутренней и за пределы Тувы), имеющих родственников почти во всех районах республики ${ }^{2}$, причем своих кровных, а также по линии супруги/супруга, с родственниками которых они также поддерживают связи. Мои респонденты стали пользоваться социальными сетями и мессенджерами несколько лет назад. Многие затруднились назвать точный год, указывая лишь «с самого начала», «как только все появилось» (т. е. с появления этих ресурсов).

Вопрос о ресурсе, чаще всего используемом для общения, подтвердил, что Viber является самым популярным среди тувинцев мессенджером³ ${ }^{3}$ причем его основная цель - «для связи со знакомыми,

организаций в доступе к информационным ресурсам. Действительно, стремительно развивающийся глобальный цифровой мир уже охватил и этот уголок мира, в котором еще в начале 2000-х годов велись общественные дискуссии относительно открытия республики для железнодорожного сообщения из-за опасений самых разных утрат - экологических, культурных и пр. Увеличивалось число жителей республики, которые не просто пользовались мобильными телефонами (уже в середине 2012 г. сотовой связью покрывалось 82\% территории Тувы), но и тех, которые хотели пользоваться расширенными возможностями связи - социальными сетями, мессенджерами, доступ к которым они получали в мобильных гаджетах - смартфонах. В 2019 г. мобильный интернет был запущен в одном из самых отдаленных уголков республики - с. Мугур-Аксы, административном центре Монгун-Тайгинского кожууна.

${ }^{1}$ По полу - 70,2\% женщин, 29,8\% мужчин. По возрастам самые значимые доли респонденты оказались у следующих групп: 35,1\% - 40-49 лет, 21,5\% - 30-35 лет, 18\% - 36-39 лет, 12,7\% - 50-60 лет. По роду занятий наиболее многочисленные группы составили: работники сферы образования - 23,4\%, работники сферы культуры - 18,5\%, научные сотрудники - 12,2\% и предприниматели - 10,2\%. Большая часть ответивших проживают в столице Тувы г. Кызыле - 66,8\%, 16,1\% оказались сельчанами, и третья значимая группа проживает за пределами Тувы - 10,7\%. Состоящих в браке - 60\%, в гражданском браке назвали себя 10,2\%, и $18 \%$ - холосты, не замужем.

${ }^{2}$ Мои респонденты указали, что их родственники - как по линии матери, так и по линии отца - почти одинаково ровно поделились в местопроживании: 39-45\% живут в столице Тувы, 42-43\% остались в прежних местах, остальные или переехали в другой район, или за пределы Тувы. Ожидаемо больше оказалась доля тех, кто поддерживает связи преимущественно с родственниками по линии матери (47,5\%), чем по линии отца (7,4\%), хотя стараются быть в ровных отношениях с обеими линиями еще $44,1 \%$. Наши женатые / замужние собеседники и собеседницы сообщили, что в большинстве своем поддерживают связи с родственниками своих половинок (40,1\% - постоянно, 19,2\% - часто, и 26,7\% - эпизодически, 14\% - практически не поддерживают).

${ }^{3}$ Мои респонденты чаще всего (по несколько раз в день) пользуются Viber (175 чел.), Instagram (125 чел.) и «ВКонтакте» (87 чел.). По 1-2 раза в день они смотрят YouTube (59 чел.), «ВКонтакте» (49 чел.), WhatsApp (44 чел.). 
родственниками» (90,2\% всех респондентов). Вторая важная задача мессенджеров - «связь с коллегами по работе» (82\%). А социальные сети в основном используются одинаково для получения информации, новостей $(76,8 \%)$ и для связи со знакомыми и родственниками $(76,4 \%)^{1}$. Почти две трети опрошенных входят в мессенджерах в группы родственников по матери (69,6\%), чуть меньше - по отцу (53,4\%), большинство общается в группах по работе с коллегами $(85,5 \%)$.

Родственные группы в мессенджерах насчитывают разное число участников, от 13 до 70 человек. Самые распространенные названия для подобных групп звучат или на тувинском языке «Төрелдер» («Родственники»), с вариациями «Эргим Төрелдер» («Дорогие родственники»), «Угбашкылар» («Сестры») и пр., или на русском - «Семья», «Родня», «Родные». Названия могут быть связаны с фамилиями (напр., «Байкаралар»), или районом («Төрелдер Улуг-Хем»). В основном такие группы появились лет пять назад, в промежутке между 2015 и 2019 гг.

Общение в группах происходит с целью обмена новостями, для поздравлений друг друга. Приведу несколько развернутых описаний, которые дали мои респонденты и в которых содержатся все типичные сюжеты и появляются схожие ситуации, связанные с подобным общением²:

«Родственники делятся фотографиями семьи, поздравляют друг друга с праздником, советы спрашивают друг у друга по поводу разных ситуаций в жизни»;

«Поздравление (день рождения), разные вопросы, домашние дела, рецепты, информация о семьи (кто что делает, как работает, как дети, события дня)»;

«Болталка (привет-пока). События в семье, например ребенок принял участие в каком-то мероприятии, открытия (где-то скидка полезных вещей, какой-то экзотический рецепт дома, как в ресторане). Обсуждение предстоящих больших мероприятий или просьбы о помощи»;

«Каждый день друг друга приветствуют, здороваются. Поздравляют с днем рождения, с юбилеем именинников. Отправляют свои фотографии. А остальные комментируют. Советуются. Иногда взрослые родственники рассказывают историю рода молодым. Иногда обсуждают ситуации в республике. Иногда играют в игры, отгадывают загадки»;

«Общаемся, шутим, желаем каждый день добра, удачи, интересуемся делами друг друга, иногда все начинаем свои фото и видео отправлять; выкладываем, что приготовили, советы просим. Иногда ругаемся. Один раз из-за конфликта и стар, и млад удалились с группы, создали отдельные группы, но со временем вновь создали единую группу»;

«Утренний и вечерние приветствия, благопожелания. Жизнь здесь и сейчас, то есть реальные ситуации в поддержке друг друга. Делимся с радостями. Планируем, когда ходить в гости, провести родовое мероприятие за год вперёд; определяем место проведения, программу согласовываем, также определяем тему для проведения родового праздника. А в хылбык дойз , свадьбе и др. мероприятиях, даже не обсуждая, все принимаем участие друг у друга. Бывает иногда советуемся, что дарить. А похороны это без обсуждения... Не только родственники, а всем, кому помог или был дорог, знаком человек, то все приходят и провожают на последний путь».

Поскольку два, три или более десятков человек в течение дня находят разные поводы поделиться чем-то, то группы в мессенджерах пополняются сообениями практически все время в течение дня (49,7\% респондентов указали именно на такую частоту). 19\% написали о сообщениях несколько раз в день, 25,1\% - «по-разному». В зависимости от уровня владения гаджетом люди могут отключать звуковые оповещения, чтобы постоянные сигналы не отвлекали. Но некоторых раздражает сама эта ситуация постоянного онлайна и звуковых оповещений (особенно если она из-за значительных часовых расхождений для проживающих за рубежом кажется почти круглосуточной) и мне отдельно писали о том, что кто-то вышел из подобных групп («надоело, что телефон все время тренькает»).

Чаще всего сообщения выкладывают женщины старше 40 лет (сестры, тети, бабушки, см. фото 1), а то и вовсе пожилого возраста, у которых больше свободного времени. В одном из чатов, например,

${ }^{1}$ По данным на январь 2021 г., в России самой популярной социальной сетью является «ВКонтакте» (запущенная с 2006 г.). Ею пользуется 46,6\% пользователей, тогда как второй по популярности является Facebook - 27,4\%. Тувинских сообществ в самой популярной российской социальной сети «ВКонтакте» на сегодня чуть более 5 тыс., численность их участников колеблется от нескольких человек до 95 тыс.

${ }^{2}$ Цитаты даются с редакторскими правками.

${ }^{3}$ Семейный праздник первой стрижки волос ребенка в 3 года. Хылбык - «волосинка», дой, или той - «праздник», «обряд». 


\section{НОВЫЕ ИССЛЕДОВАНИЯ ТУВЫ}

www.nit.tuva.asia

участвуют несколько бабушек в возрасте 70-80 лет, которые специально просили детей поменять им простые кнопочные телефоны на смартфоны, чтобы пользоваться социальными сетями и мессенджерами.

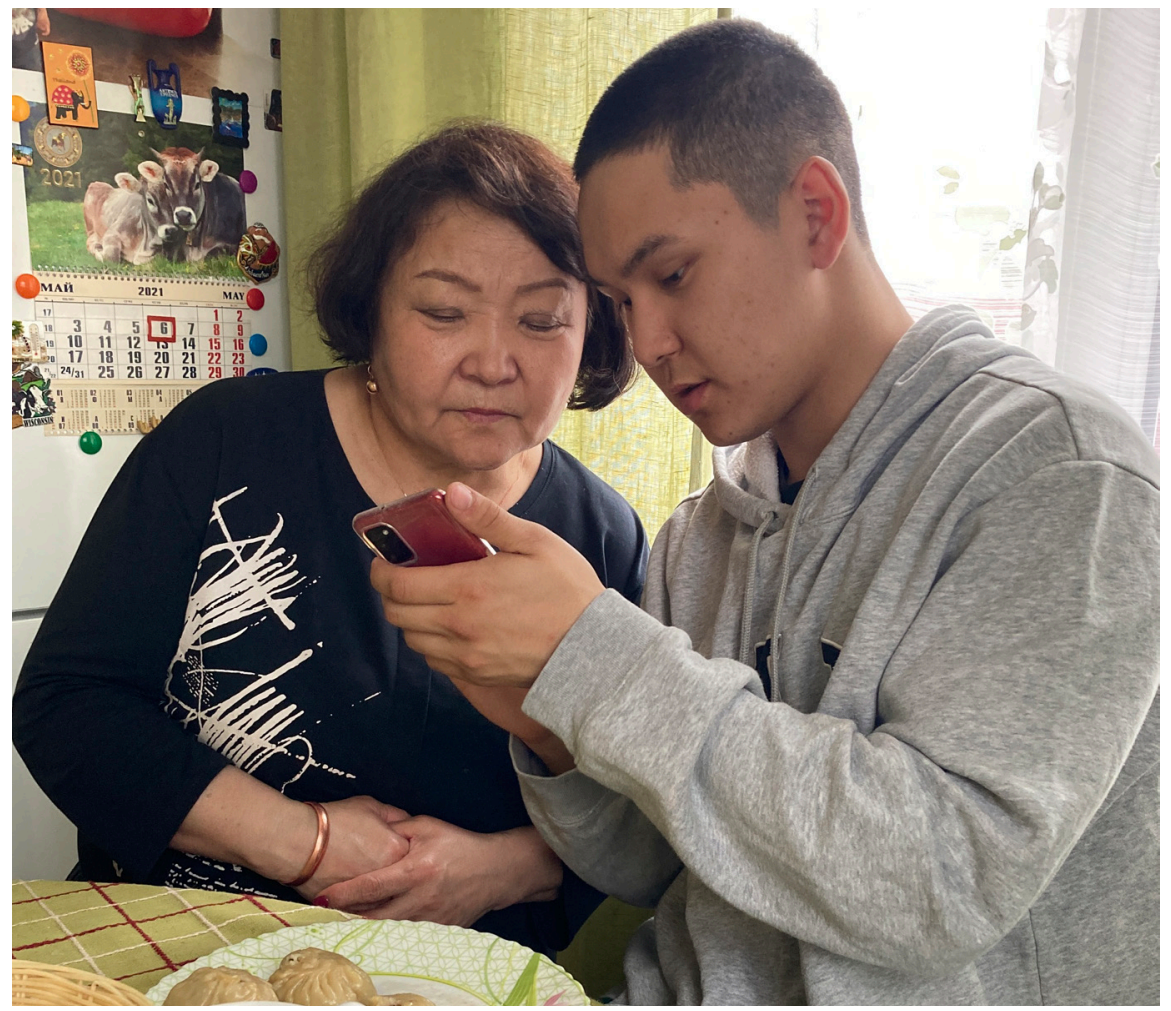

Фото 1. Внук объясняет бабушке, как пользоваться мобильными приложениями на смартфоне. Фото автора, 2020 2.

Photo 1. The grandson is explaining to the grandmother how to use mobile applications on the smartphone. Photo by the author, 2020.

Учитывая то, что хозяйки встают рано, то и с утра пораньше чаты наполняются именно их приветствиями, различными мотивирующими фотографиями (рис. 1 и 2).

Общение ведется в основном на тувинском языке (в группах у $32 \%$ респондентов), или в равной мере на русском и тувинском языках (у 33,7\%). Но есть и определенные группы (у 22\%), где принято переписываться только на тувинском языке. В комментариях мне писали, что это не обязательно четко установленное правило, но его соблюдают. В некоторых группах есть и специальные правила: «лайкать» то, что понравилось и комментировать, не писать на русском языке, не ссориться, не материться, уважать старших; обязательно приветствовать, поздравлять друг друга и пр.

На вопрос «Как вы считаете, а нужны ли правила в подобных группах и какие именно?» отвечали по-разному. Здесь я получила достаточно много рассуждений, тема явно наболела:

«Правила должны быть. Например, не нужно всякий раз отправлять спам, картинки с пожеланиями (с добрым утром, хорошего дня и т. д.)»;

«Хочу, чтобы все мы общались на тувинском языке, т. к. внуки не знают родной тувинский язык»;

«Правила нужны, т. к. в группе есть представители старшего, среднего и младшего поколения родственников»;

«Да нужны: не пересылать одни и те же длинные информации по гороскопу, типу людей, советы, рецепты, приколы, новости, прогнозы и т. д.» и др.

Большинство респондентов считает подобные группы важными, поскольку их наличие позволяет узнавать о жизни родственников (85\%), оповещать их о новостях из своей жизни (81\%) и наличие такого чата позволяет быстро принимать коллективные решения (71\%). В целом поддерживать связи тувинцев с их родственниками важными считают $86 \%$, и использование социальных сетей, мобильных мессенджеров позволяет распространять важную информацию (76,6\%). 


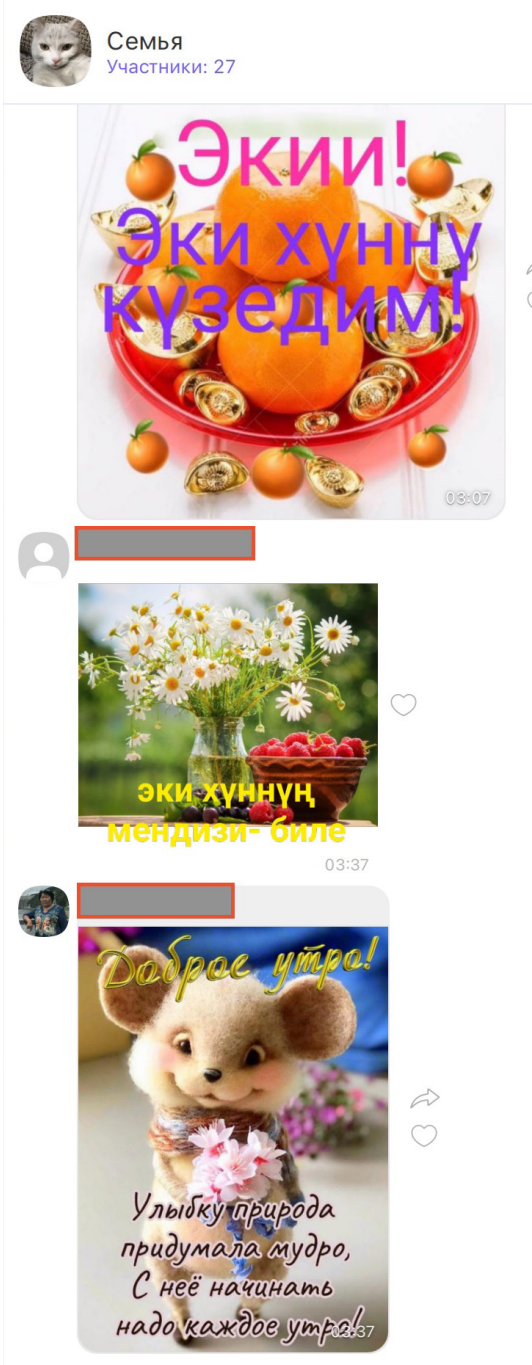

Рис. 1. Скриншот страницы группы «Семья» (одной из родственных групп западных тувинцев) в Viber с утренним обменом приветствиями. Fig 1. Screenshot of the group page "Family" (one of the kin groups of Western Tuvans) on Viber presenting the exchange of morning greetings.

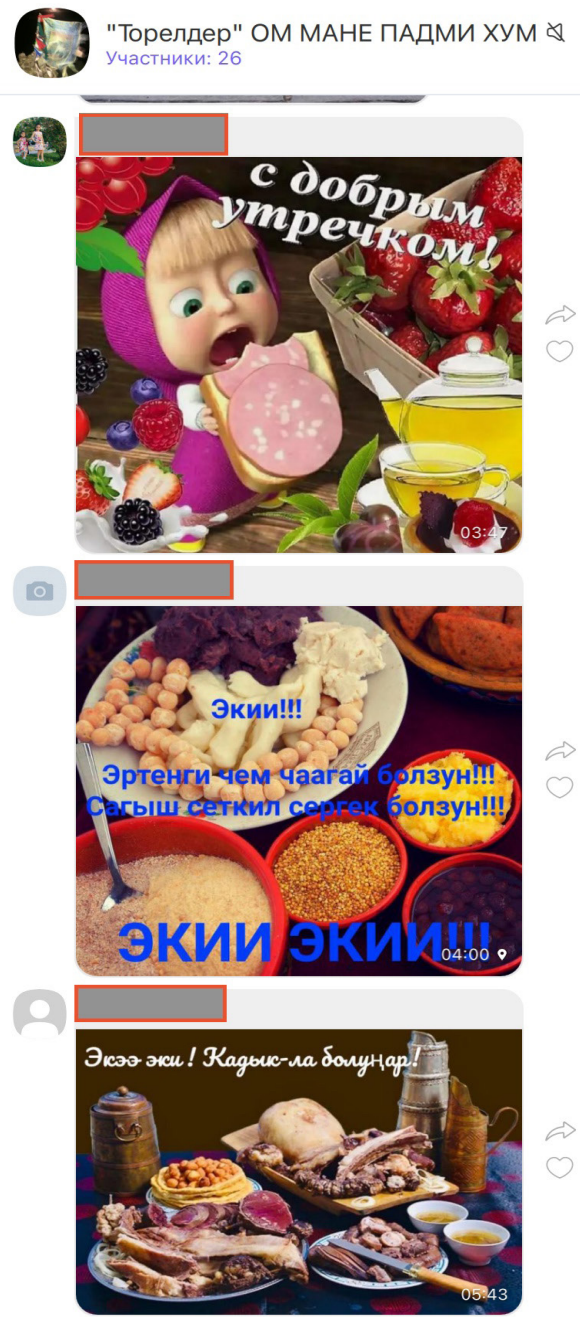

Рис. 2. Скриншот страницы группы “"Торелдер”. ОМ МАНИ ПАДМИ ХУМ» (одной из родственных групп южных тувинцев) в Viber с утренним обменом приветствиями.

Fig. 2. Screenshot of the group page "'Torelder'. OM MANI PADMI KHUM" (one of the kin groups of South Tuvans)

on Viber presenting the exchange of morning greetings.

Разумеется, родственники, проживающие в одном поселении, городе, имеют возможности для регулярных личных встреч и общения. Однако, многие осознали удобство мессенджеров для веерных оповещений вне зависимости от местонахождения друг друга, с экономией сил и времени. В чатах рассылают приглашения на семейные мероприятия, оповещают о дате, месте и времени встреч. Там же составляют списки, распределяют обязанности, договариваются. Это средство для мгновенного оповещения, для синхронизации действий родственных групп было оценено в период пандемии и многомесячного вынужденного заточения людей по домам в 2020 г. 57,4\% респондентов сообщили, что тувинцы однозначно стали больше использовать социальные сети и мессенджеры в этот период, $23,5 \%$ - «возможно стали больше использовать». Но интересен также тот факт, что еще $23 \%$ значительной разницы в степени использования не ощутили.

\section{Этническая солидарность и Интернет-конкурсы}

Надо сказать, что использование интернет-коммуникаций именно как возможность сплочения, координации общих действий позволяет тувинцам максимально результативно участвовать во всевозможных всероссийских и даже международных голосованиях в Интернет-конкурсах. Основной 
контингент голосующих обеспечивается именно за счет земляков, поскольку организаторам важно только общее количество голосов и географических ограничений они не делают.

Приведу несколько примеров подобных успешных земляческих «штурмов»:

- на конкурсе красоты «Мисс Россия 2018», финал которого состоялся 14 апреля 2018 г., победителем номинации «Народный выбор» после активного голосования пользователей интернет-партнера конкурса стала финалистка из Тувы Норгьянмаа Монгуш. За нее проголосовало 54799 человек ${ }^{1}$;

- в январе 2019 г. в финале всероссийского вокального конкурса «Новая звезда 2019» телеканала «Звезда» было объявлено смс-голосование на приз зрительских симпатий. Победителями стала музыкальная семья Айыжы (три сестры и брат) из Тувы. Они получили наибольшее число голосов 95313';

- в итоге интернет-голосования сайта «Скульптутура» на выбор самого необычного памятника России, который прошел осенью 2020 г., памятник тувинской письменности в музее-заповеднике «Белдир-Кежик» (скульпторы А. Ойдуп и А. Миронов, 2016) занял первое место с суммой голосов 315773;

- на международном конкурсе красоты «Лицо Азии 2020», который проходил в условиях пандемии в онлайн-режиме (хотя основная организация была в Южной Корее), по итогам суммы голосов экспертного мнения (50\%) и голосования людей в мобильном приложении (50\%), победительницей была признана участница из Тувы Чечена Кыргыс

- третье место в интернет-голосовании Первого национального конкурса региональных брендов продуктов питания 2020 г., организованного Министерством сельского хозяйства РФ, заняла тувинская баранина в номинации «Попробуй, полюбишь»

Подобных результатов позволяет добиваться не только массовая рассылка призыва голосовать, но и действительно важная для тувинцев земляческая, этническая солидарность. Она побуждает и голосовать (предпринимая целый ряд технических действий: включать устройство, заходить на определенный ресурс каждый день, нажимать на соответствующие кнопки), и с азартом следить за ходом голосования, подбадривать друг друга и призывать голосовать других людей. Такое поведение демонстрирует даже глава республики Ш. В. Кара-оол' ${ }^{6}$ который также делает в соцсетях репосты, пишет обращения к землякам и болеет за «своих» ${ }^{7}$.

Очевидно, что увлеченность представителей этнических групп подобными голосованиями приводит к тому, что эта земляческая активность и солидарность становятся объектом внимания интернетмаркетинга различных бизнес-проектов. Но, похоже, членов этнической общности, население региона это не волнует. Призывы к интернет- и смс-голосованию, к увеличению количества голосов «за своих» звучат как в социальных сетях, распространяются в мессенджерах, так и передаются в местных СМИ, распространяются от членов правительства региона.

Повышенная интернет-активность тувинцев также выявилась в ходе опроса моей коллеги Н. Д. Сувандии по вопросам празднования тувинцами Шагаа - Нового года по лунному календарю. Он был

\footnotetext{
${ }^{1}$ Финал конкурса «Мисс Россия 2018» [Электронный ресурс] // Мисс Россия. Национальный конкурс. 2018, 14 апреля. URL: http://www.missrussia.ru/press-center/news/inside-210 (дата обращения: 12.04.2021).

${ }^{2}$ Музыкальная семья Айыжы из Тувы объединила земляков, получила мощную поддержку и выиграла зрительский приз в телеконкурсе «Новая звезда» и 1 млн. рублей [Электронный ресурс] // ИА Тува-онлайн. 2019, 14 января. URL: https://www.tuvaonline.ru/2019/01/14/muzykalnaya-semya-ayyzhy-iz-tuvy-obedinila-zemlyakovpoluchila-moschnuyu-podderzhku-i-vyigrala-zritelskiy-priz-v-telekonkurse-novaya-zvezda-i-1-mln-rubley.html (дата обращения: 12.04.2021).

${ }^{3}$ Россияне выбрали самый необычный памятник [Электронный ресурс] // РИA Новости. 2021, 14 января. URL: https://ria.ru/20210114/pamyatnik-1592953992.html (дата обращения: 12.04.2021).

${ }^{4}$ Россиянка Чечена Кыргыс (Тува) выиграла Международный конкурс «Лицо Азии» [Электронный ресурс] // ИА Тува-онлайн. 2020, 7 декабря. URL: https://www.tuvaonline.ru/2020/12/07/rossiyanka-chechena-kyrgys-tuvavyigrala-mezhdunarodnyy-konkurs-lico-azii.html (дата обращения: 12.04.2021).

${ }^{5}$ Вкусы России: https://russiantastes.ru/. См. также: Голосуем за тувинскую баранину! [Электронный ресурс] // Тувинская правда. URL: https://tuvapravda.ru/post/golosuem-za-tuvinskuju-baraninu (дата обращения: 12.04.2021).

67 апреля 2021 г. подал в отставку: https://ria.ru/20210407/tuva-1727211586.html. - peд.

${ }^{7}$ Глава Тувы Ш. В. Кара-оол признан одним из самых активных российских губернаторов - пользователей социальных сетей. См.: Шолбан Кара-оол назван самым популярным губернатором в Сибири и ДФО [Электронный ресурс] // Золотая орда. 2019, 4 февраля. URL: https://zolord.ru/новости/шолбан-кара-оолназван-самым-популярным-губернатором-в-сибири-и-дфо (дата обращения: 12.04.2021).
} 
проведен также в Google Forms накануне очередного праздника - в январе и феврале 2021 г. ${ }^{1}$ Сама анкета была составлена на тувинском языке, и информация о ней распространялась схожим путем рассылкой по социальным сетям тувинцев, группам в мессенджерах. Менее чем за месяц было собрано методом «снежного кома» 858 заполненных анкет от тувинцев самых разных возрастов и местожительства.

\section{Социальная культура тувинцев и типы пространства}

Как пишет К. Хайн, Интернет, «убивающий» расстояние, позволяет поддерживать отношения по всему миру, независимо от местоположения и часового пояса (Hine, 2000: 84). Ссылаясь на идеи M. Кастельса о развитии цифрового общества (Castells, 1996), она подчеркивает, что произошла замена пространства мест на пространство потоков. И в пространстве потоков, который обеспечивает альтернативный способ ведения социальных отношений, акцент делается на связи, а не на местоположении (Hine, 2000: 85).

Рассмотрим, как этот процесс происходил у тувинцев.

Их социокультурная жизнь имела свои особенности в разные времена и складывались в определенных условиях в зависимости от социальной политики государства - по периодам: традиционный (с середины XVIII в. до начала XX в.), советский (1930-1990 гг.) и кризисно-архаизационный (1990-2010 гг.). В 2010-х годах, очевидно, появился и продолжает развиваться новый период.

Особенности в целом традиционной культуры тувинцев, как уже сформировавшегося этноса ${ }^{2}$, в этнографической литературе часто рассматривают с момента включения Тувы в состав Маньчжурской империи Китая в середине XVIII в. Китай установил ту систему административно-территориального устройства края, которая упорядочила общественную жизнь огромного числа племен. Тувинцы получили систему централизованного управления, социальная дифференциация была выстроена по линии совмещения и богатств, и соподчиненности иноземным властям (История Тувы, 2001: 266-273). Это повлияло на дальнейшее формирование социальной идентичности кочевников. Если сначала они объединялись в родоплеменные группы и идентифицировали себя именно в связи с этим фактором, то, как отмечают исследователи, в конце XIX века тувинцы уже идентифицировали себя скорее по административному делению (см.: Дулов, 1956: 116).

Тем не менее, хошуны (основные единицы административного деления во времена маньчжурского правления) состояли из сумонов и арбанов, которые объединяли, как правило, близких родственников, сородичей (Потапов, 1969: 43). Впоследствии маньчжурско-китайская политика замены родственной солидарности территориальной идентификацией была продолжена советской политикой. Однако, полной замены не произошло ни в китайское время, ни в советское. Родственные связи для тувинцев остались очень важными.

Дело в том, что значимость социальных связей тувинцев была основана на правилах аальной общины - аала (История Тувы, 2001: 273), прежде всего традиционного типа, когда общность была на кровном родстве семей. Помимо этого, также были и аллы типа соседских общин, а также аальные байские хозяйства. В целом хозяйственная деятельность любого типа аалов подразумевала существенные внутренние экономические связи, различные формы взаимопомощи, круговую поруку, обычаи делиться охотничьей добычей и пр. (там же: 274). Идентификация «своих» основывалась на том, что эти «свои» жили рядом. И вся социальная культура была «привязана» к определенной территории, разворачивалась на знакомом пространстве. Картина мира с ее членением на зоны (свое пространство - свои люди, чужое пространство - чужие люди) имеет древние корни и ее общие характеристики известны для тюркоязычных народов всего региона Южной Сибири (Традиционное мировоззрение ..., 1988).

Социальная политика советского типа, которая начала разворачиваться в Тувинской Народной Республике во главе с С. К. Тока с 1930 г. и развивалась далее в русле эволюции советского государства (в который Тува вошла в 1944 г.), считается кардинальной и в ряде случаев даже радикальной. Это была силовая мобилизация советского типа, когда государство формировало новый - прогрессивный тип советского человека и, в том числе избавляло народы от «темного прошлого». Кочевые народы в

${ }^{1}$ Благодарю Надежду Дарыевну Сувандии за любезное согласие озвучить эти данные в моей статье. Результаты самого исследования коллега готовит в виде авторской научной статьи.

${ }^{2}$ О формировании тувинцев как этноса в XVII - начале XVIII в. см. Маннай-оол, 2004: 100-101. 
этом случае переводили на оседлость, им прививали «прогрессивный» образ жизни (Ламажаа, 2011: 68-85). Расселение тувинцев в стационарных жилищах, формирование совхозов, образование, работа в определенных отраслях экономики в соответствии с новыми профессиями - всё это привело к тому, что прежние родовые группы распались. Их члены разъехались и пространство социальной культуры локальных групп в виде конкретной местности (место-пространство) потеряло свою прежнюю значимость. Там остались жить лишь отдельные семьи животноводов.

Родственные группы, помня об общем месте исхода, месте-пространстве, которое их единило, все же сохранили и, возможно, даже укрепили связи. Пространство социальной культуры «растянулось» в географическом смысле, став регион-пространством. В конце 1970-х гг., в период «развитого социализма», социологи зафиксировали материальную взаимопомощь тувинцев-родственников: сельские жители оказывали своим родным в городе помощь сельхозпродуктами, а те - предметами культурно-бытового назначения, одеждой, обувью, деньгами (Очерки социального ... , 1983: 79). И, как выяснилось совсем недавно, эта же стратегия взаимопомощи домохозяйств родственников сельчан и горожан - сохранилась и до сегодняшнего дня (Социально-стратификационные ... , 2020: 85, 87-88).

Ш. Степанофф отмечал, что парадоксальный результат коммунистической политики был связан с русской системой фамилий в жизни тувинцев, которая позволила «заморозить» систему широких родственных групп в представлениях людей, поскольку фамилии были присвоены в соответствии с «родовой» принадлежностью (Степанофф, 2009: 131-132). Но, полагаю, что это был лишь один из комплекса факторов, который в целом еще необходимо изучать.

Когда советский образ жизни был отвергнут, то Тува вместе с остальными постсоветскими территориями, с российскими регионами, оказалась вовлеченной в модернизационный процесс, ставший неотъемлемой частью мировых процессов в глобальном мире. Однако кризис реформирования на всем постсоветском пространстве привел к разворачиванию ответного социального механизма процессу архаизации, когда люди в отсутствие социальных гарантий, в условиях экономического кризиса, политической неустойчивости и отказа от прежней идеологии стихийно обратились к архаическим социальным связям, социальным институтам, позволявшим им выживать в сложных условиях (Ламажаа, 2012). Этот процесс охватил все сферы жизни общества, в политической области он выразился в расцвете клановости во власти (Ламажаа, 2010).

В том числе обращение к стратегии взаимопомощи общин, поддержание связей между родственниками у тувинцев на регион-пространстве также стало одним из проявлений архаизации. В 1990-е годы обмен продуктами питания, непродовольственными товарами, наличными деньгами между городскими и сельскими тувинцами стал одним из важнейших средств для выживания. По дорогам республики активно курсировал транспорт для перевозки людей, продуктов, товаров. Тема связи между родственниками, взаимопомощи стала как никогда актуальной и в значительной степени семейные торжества (праздники стрижки детей, свадьбы, юбилеи), также как и похороны, стали проводиться для сбора средств одной семье силами расширенной семьи родственников ${ }^{1}$.

Улучшение социально-экономической ситуации по всей стране в 2000-е годы, а также появление нового пространства для связей между людьми, который образовался благодаря мобильной связи, беспроводному Интернету - онлайн-пространства, или пространства потока (по К. Хайн) - способствовали тому, что социальная культура тувинцев получила дополнительное поле, более обширное, чем регион-пространство, в целом нивелирующее географическую основу пространства. А 2020 год, год начала пандемии COVID-19, вынудивший человечество разрывать социальные связи для предотвращения распространения опасного вируса, способствовал еще большему его освоению. Разумеется, эти тенденции глобальны, но локальные сообщества могут демонстрировать их разные местные вариации.

Исторический экскурс позволяет увидеть, что пространство социальной культуры тувинцев подвергалась на протяжении истории изменениям, а социальная культура сохранила свои основные ценности - значимость социальных связей родственных групп.

${ }^{1}$ Тот факт, что родственные связи для тувинцев остались очень важными, был показан в нашей общей с филологами работе на примере обширной терминологии производных слов от слова төрел (родственник) в тувинском языке и в целом в языковой картине мира (Кужугет и др., 2019). 


\section{Заключение}

Распространенное пользование социальными сетями, мессенджерами рядом авторов может рассматриваться с точки зрения их негативного воздействия - для разобщения людей (когда говорят об одиночестве в сети, отчуждении и потери общества, изоляции друг от друга и пр.). Но очевидно, что у этого современного канала коммуникаций есть и другая сторона, когда она действительно помогает поддерживать и даже укреплять связи общностей - этнических, локальных, земляческих. Однако, сами эти связи не являются чем-то новым. Я попыталась показать, как родственные отношения тувинцев, не утратившие своей актуальности и важности более чем за век трансформационных перемен самого тувинского общества, стали актуальными как часть архаизационного процесса конца XX в. Их пространство местопроживания родовой общности стало больше ментальным образом, маркером идентификации; само пространство социального взаимодействия сначала расширилось в географическом плане, а потом географическое измерение перестало быть существенным. Тувинцы, как и остальной мир, успешно перешли в социальных связях на пространство онлайн-потока. И в этом переходе для них наиболее важным стало то, что онлайн-пространство позволяет им поддерживать значимые известные связи - связи со своими родственниками, земляками. Если в целом методы пользования интернет-коммуникациями людей подобны общемировым тенденциям, то этническое измерение выражается именно в этносоциальной солидарности и самоорганизации.

Разумеется, тема онлайн-пространств социальных общностей, нивелирующих проблему места, вызывает новые вопросы. Упоминавшийся Г. Рейнгольд в своей еще более ранней работе «Виртуальная община» (Rheingold, 1993; второе издание: Rheingold, 2000), констатируя углубление социального воздействия через Интернет, уже в 1990-х гг. подчеркивал, что технология не должна предопределять направленность динамики социальных отношений (Рейнгольд, 2013: 244). Но в случае с этническими особенностями пространств потока, мы можем говорить, что здесь возможны совмещения процессов: социальная культура не изменилась из-за технологий, а лишь нашла в них свой путь дальнейшего развития. Очевидно, что строго возврата к прошлому все равно не будет, новации могут внести свои коррективы в социальную эволюцию этнических сообществ и этнические идентификации. Поэтому список вопросов для анализа будет еще пополняться.

\section{СПИСОК ЛИТЕРАТУРЫ}

Абрамов, Р. Н. (2006) Мобильные коммуникационные технологии и повседневность. Рейнгольд Г. Умная толпа: новая социальная революция. М.: Фаир-Пресс, 2006. - 416 с. // Журнал социологии и социальной антропологии. T. 9, № 4. С. 185-192.

Белоруссова, С. Ю., Головнев А. В. (2019) Виртуальная этничность и киберэтнография // Сибирские исторические исследования. № 2. С. 36-40. DOI: https://doi.org/10.17223/2312461X/24/2

Быльева, Д. С., Лобатюк, В. В. (2017) Смартмоб: социально-философский анализ // Научно-технические ведомости СПбГПУ. Гуманитарные и общественные науки. Т. 8, № 4. С. 96-107. DOI: https://doi.org/10.18721/JHSS.8410

Васильев, А. В., Коркия, Э. Д., Мамедов А. К. (2019) Культура коммуникаций в условиях информационной глобализации. М. : Макс-Пресс. 160 с.

Габдрахманова, Г. Ф., Махмутов, З. А. (2018) Национальный интернет России: к постановке проблемы // Oriental Studies. T. 11. № 3. C. 142-151. DOI: https://doi.org/10.22162/2619-0990-2018-37-3-142-151

Головнёв, А. В. (2018) Этнография в российской академической традиции // Этнография. № 1. C. 6-39. DOI: https://doi.org/10.31250/2618-8600-2018-1-6-39

Головнёв, А. В. (2019) Кружение в кочевом и виртуальном пространстве-времени // Сибирские исторические исследования. № 2. С. 108-131. DOI: https://doi.org/10.17223/2312461X/24/6

Головнев, А. В., Белоруссова, С. Ю., Киссер, Т. С. (2018) Виртуальная этничность - новация на фоне традиции? (Введение в тему) // Уральский исторический вестник. № 1. С. 100-108. DOI: https://doi.org/10.30759/1728-97182018-1(58)-100-108

Дулов, В. И. (1956) Социально-экономическая история Тувы. ХІХ - начало XX в. М. : Изд-во Академии наук СССР. 595 c.

История Тувы (2001) / под ред. С. И. Вайнштейна, М. Х. Маннай-оола. 2-е изд. Новосибирск : Наука. Т. 1.371 с.

Киссер, Т. С. (2019) Виртуальная идентичность российских немцев // Сибирские исторические исследования. № 2. C. 64-84. DOI: https://doi.org/10.17223/2312461X/24/4 
Кужугет, Ш. Ю., Сувандии, Н. Д., Дамбаа, Ш. В., Ламажаа, Ч. К. (2019) Концепт төрел 'родственник’ в языковой картине мира тувинцев // Новые исследования Тувы. № 3. С. 149-157. DOI: https://doi.org/10.25178/nit.2019.3.12

Ламажаа, Ч. К. (2010) Клановость в политике регионов России. Тувинские правители. СПб. : Алетейя. 206 с.

Ламажаа, Ч. К. (2011) Тува между прошлым и будущим. 2-е изд. СПб. : Алетейя. 368 с.

Ламажаа, Ч. К. (2012) Архаизация общества. Тувинский феномен. М. : Книжный дом «Либроком». 270 с.

Ламажаa, Ч. К. (2021) Тувинские обряды дагылга в XXI веке // Этнографическое обозрение. № 2. C. 125-143. DOI: https://doi.org/10.31857/S086954150014811-2

Маннай-оол, М. Х. (2004) Тувинцы: Происхождение и формирование этноса. Новосибирск : Наука. 166 с.

Мартьянов, Д. С., Мартьянова, Н. А. (2012) Дискурсивные аспекты этнической идентичности в интернете // Вестник СГУТиКД. № 2 (20). С. 233-238.

Махмутов, 3. А., Габдрахманова, Г. Ф. (2016) Особенности этнической идентичности виртуальных татарских сообществ в социальной сети ВКонтакте // Историческая этнология. Т. 1, № 2. С. 276-292.

Очерки социального развития Тувинской АССР (1983) / В. И. Бойко, В. Н. Белошапкина, Г. Ч. Ширшин и др. Новосибирск : Наука. 264 с.

Потапов, Л. П. (1969) Очерки народного быта тувинцев. М. : Наука. 402 с.

Рейнгольд, Г. (2006) Умная толпа : новая социальная революция / пер. с англ. М. : Фаир-Пресс. 416 с.

Рейнгольд, Г. (2013) Переосмысляя феномен виртуального сообщества // Studia Culturae. № 15. C. $243-250$.

Смирнов, Д. Н. (2008) Политическое манипулирование и технология «умных толп» как средства борьбы за гегемонию // Известия Российского государственного педагогического университета им. А. И. Герцена. № 67. C. 247-251.

Социально-стратификационные процессы в Республике Тыва (2020) / 3. Т. Голенкова и др.; отв. ред. 3. Т. Голенкова, Ю. В. Голиусова, П. Е. Сушко; ФНИСЦ РАН. М. ; Кызыл : ФНИСЦ РАН. 128 с. DOI: https://doi.org/10.19181/ monogr.978-5-89697-332-4.2020

Степанофф, Ш. (2009) Метаморфозы родства у тувинцев // Этнографическое обозрение. № 4. С. $129-145$.

Сулейманова, О. А. (2020) Презентация культуры кольских саамов в социальной сети «Вконтакте»: динамика визуальных образов материальной культуры // Этнография. № 3. С. 169-199. DOI: https://doi.org/10.31250/26188600-2020-3(9)-169-199

Традиционное мировоззрение тюрков Южной Сибири. Пространство и время. Вещный мир (1988) / Э. Л. Львова, И. В. Октябрьская, А. М. Сагалаев, М. С. Усманова. Новосибирск : Наука. 226 с.

Castells, M. (1996) The rise of the network society. Cambridge, MA : Blackwell. 625 p.

Ethnography and virtual worlds: A handbook of method (2012) / T. Boellstorff, B. Nardi, C. Pearce, T. L. Taylor. Princeton ; Oxford : Princeton University Press. 264 p. DOI: https://doi.org/10.2307/j.cttq9s20

Hine, C. (2000) Virtual ethnography. London; Thousand Oaks ; New Delhi : Sage Publications Ltd. 192 p.

Marcus, G. (2012) Foreword// Ethnography and virtual worlds: A handbook of method/T. Boellstorff, B. Nardi, C. Pearce, T. L. Taylor. Princeton ; Oxford : Princeton University Press. P. XIII-XX. DOI: https://doi.org/10.2307/j.cttq9s20.4

Markham, A. N. (2013) Fieldwork in social media. What would Malinowski do? // Qualitative Communication Research. Vol. 2, No. 4, Winter. P. 434-446. DOI: https://doi.org/10.1525/qcr.2013.2.4.434

Rheingold, H. (1993) The virtual community: Homesteading on the electronic frontier. Reading, MA, Addison-Wesley. $325 \mathrm{p}$.

Rheingold, H. (2000) The virtual community: Homesteading on the electronic frontier. 2 ed. Cambridge, MA, MIT Press. Rheingold, H. (2002) Smart mobs: The next social revolution. Cambridge, MA : Perseus Pub. 296 p.

Дата поступления: 26.04.2021 2.

\section{REFERENCES}

Abramov, R. N. (2006) Mobil'nye kommunikatsionnye tekhnologii i povsednevnost'. Reingol'd G. Umnaia tolpa: novaia sotsial'naia revoliutsiia. M.: Fair-Press, 2006. - 416 s. [Mobile communicative technologies and everyday life. Howard Rheingold's “Smart Mobs: The Next Social Revolution” (Moscow, Fair-Press, 2006. 416 p.)]. The Journal of Sociology and Social Anthropology, vol. 9, no. 4, pp. 185-192. (In Russ.).

Belorussova, S. Yu. and Golovnev A. V. (2019) Virtual'naia etnichnost' - novatsiia na fone traditsii? (Vvedenie v temu) [Is virtual ethnicity a novel phenomenon in the context of tradition? (Introduction to the special issue theme)]. Siberian Historical Research, no. 2, pp. 36-40. (In Russ.). DOI: https://doi.org/10.17223/2312461X/24/2 
Byl'eva, D. S. and Lobatiuk, V. V. (2017) Smartmob: sotsial'no-filosofskii analiz [Smart mob: A socio-philosophical analysis]. Society. Communication. Education. Peter the Great St. Petersburg Polytechnic University, vol. 8, no. 4, pp. 96-107. (In Russ.). DOI: https://doi.org/10.18721/JHSS.8410

Vasil'ev, A. V., Korkiia, E. D. and Mamedov A. K. (2019) Kul'tura kommunikatsii v usloviiakh informatsionnoi globalizatsii [Culture of communications in the conditions of information globalization]. Moscow, Maks-Press. 160 p. (In Russ.).

Gabdrakhmanova, G. F. and Makhmutov, Z. A. (2018) Natsional'nyi internet Rossii: k postanovke problemy [National Internet of Russia: Problem statement revisited]. Oriental Studies, vol. 11, no. 3, pp. 142-151. (In Russ.). DOI: https://doi. org/10.22162/2619-0990-2018-37-3-142-151

Golovnev, A.V.(2018) Etnografiia v rossiiskoi akademicheskoi traditsii [Ethnography in the Russian academic tradition]. Etnografia, no. 1, pp. 6-39. DOI: https://doi.org/10.31250/2618-8600-2018-1-6-39

Golovnev, A. V. (2019) Kruzhenie v kochevom i virtual'nom prostranstve-vremeni [Circling in nomadic and virtual space-time]. Siberian Historical Research, no. 2, pp. 108-131. (In Russ.). DOI: https://doi.org/10.17223/2312461X/24/6

Golovnev, A. V., Belorussova, S. Yu. and Kisser, T. S. (2018) Veb-etnografiia i kiberetnichnost' [Web-ethnography and cyber-ethnicity]. Ural Historical Journal, issue 1, pp. 100-108. DOI: https://doi.org/10.30759/1728-9718-2018-1(58)-100108

Dulov, V. I. (1956) Sotsial'no-ekonomicheskaia istoriia Tuvy. XIX - nachalo XX v. [The socio-economic history of Tuva. The 19th - early 20th centuries]. Moscow, Publ. House of the Academy of Sciences of the USSR. 608 p. (In Russ.).

Istoriia Tuvy [The history of Tuva] (2001) : in 2 vols. 2nd ed. / ed. by S. I. Vanshtein and M. Kh. Mannai-ool. Novosibirsk, Nauka. Vol. I. 367 p. (In Russ.).

Kisser, T. S. (2019) Virtual'naia identichnost' rossiiskikh nemtsev [The virtual identity of the Russian Germans]. Siberian Historical Research, no. 2, pp. 64-84. (In Russ.). DOI: https://doi.org/10.17223/2312461X/24/4

Kuzhuget, Sh. Yu., Suvandii, N. D., Dambaa, Sh. V. and Lamazhaa, Ch. K. (2019) Kontsept törel 'rodstvennik' v iazykovoi kartine mira tuvintsev [The concept of torel ('relative') in the Tuvan linguistic world picture]. New Research of Tuva, no. 3, pp. 149-157. (In Russ.). DOI: https://doi.org/10.25178/nit.2019.3.12

Lamazhaa, Ch. K. (2010) Klanovost'v politike regionov Rossii. Tuvinskie praviteli [The clan politics of Russia's regions. The leaders of Tuva]. St. Petersburg, Aletheia. 208 p. (In Russ.).

Lamazhaa, Ch. K. (2011) Tuva mezhdu proshlym i budushchim [Tuva between the past and future]. St. Petersburg, Aletheia. 368 p. (In Russ.).

Lamazhaa, Ch. K. (2012) Arkhaizatsiia obshchestva. Tuvinskii fenomen [Archaization of the society. Tuvan phenomenon]. Moscow, Publ. House “Librokom”. 272 p. (In Russ.)

Lamazhaa, Ch. K. (2021) Tuvinskie obriady dagylga v XXI veke [Tuvan rites dagylga in the 21st century]. Etnograficheskoe obozrenie, no. 2, pp. 125-143. (In Russ.). DOI: https://doi.org/10.31857/S086954150014811-2

Mannai-ool, M. Kh. (2004) Tuvintsy: proiskhozhdenie i formirovanie tuvinskogo etnosa [Tuvans: The origin and formation of the Tuvan ethnos]. Novosibirsk, Nauka. 166 p. (In Russ.).

Mart'ianov, D. S. and Mart'ianova, N. A. (2012) Diskursivnye aspekty etnicheskoi identichnosti v internete [Discursive aspects of ethnic identity on the Internet]. Vestnik SGUTiKD, no. 2 (20), pp. 233-238. (In Russ.).

Makhmutov, Z. A. and Gabdrakhmanova, G. F. (2016) Osobennosti etnicheskoi identichnosti virtual'nykh tatarskikh soobshchestv v sotsial'noi seti VKontakte [Features of ethnic identity of Tatar virtual communities in the "VKontakte" social network]. Istoricheskaia etnologiia, vol. 1, no. 2, pp. 276-292. (In Russ.).

Ocherki sotsial'nogo razvitiia Tuvinskoi ASSR [Essays on social development of the Tuvan ASSR] (1983) / ed. by Yu. L. Aranchyn. Novosibirsk, Nauka. 262 p. (In Russ.).

Potapov, L. P. (1969) Ocherki narodnogo byta tuvintsev [The Tuvans: Sketches of the folk lifestyle and related household activities]. Moscow, Nauka, GRVL. 402 p. (In Russ.).

Rheingold, H. (2006) Umnaia tolpa: novaia sotsial'naia revoliutsiia [Smart mobs: The next social revolution]/ transl. from Engl. Moscow, Fair-Press. 416 p. (In Russ.).

Rheingold, H. (2013) Pereosmysliaia fenomen virtual'nogo soobshchestva [Rethinking virtual communities]. Studia Culturae, no. 15, pp. 243-250. (In Russ.).

Smirnov, D. N. (2008) Politicheskoe manipulirovanie i tekhnologiia «umnykh tolp» kak sredstva bor'by za gegemoniiu [Political manipulation and smart mob technology as means of struggle for hegemony]. Izvestia: Herzen University Journal of Humanities \& Sciences, no. 67, pp. 247-251. (In Russ.). 
НОВЫЕ ИССЛЕДОВАНИЯ ТУВЫ

www.nit.tuva.asia

Sotsial'no-stratifikatsionnye protsessy v Respublike Tyva [Socio-stratification processes in the Republic of Tuva] (2020) / Z. T. Golenkova et al., ed. by Z. T. Golenkova, Yu. V. Goliusova and P. E. Sushko. Moscow; Kyzyl, FCTAS RAS. 128 p. DOI: https://doi.org/10.19181/monogr.978-5-89697-332-4.2020

Stépanoff, Ch. (2009) Metamorfozy rodstva u tuvintsev [Metamorphoses of kinship among Tuvans]. Etnograficheskoe obozrenie, no. 4, pp. 129-145. (In Russ.).

Suleimanova, O. A. (2020) Prezentatsiia kul'tury kol'skikh saamov v sotsial'noi seti «Vkontakte»: dinamika vizual'nykh obrazov material'noi kul'tury [Presentation of the culture of the Kola Sami in VKontakte social network: The dynamics of the visual images of material culture]. Etnografia, no. 3, pp. 169-199. DOI: https://doi.org/10.31250/2618-86002020-3(9)-169-199

Traditsionnoe mirovozzrenie tiurkov Iuzhnoi Sibiri. Prostranstvo i vremia. Veshchnyi mir [The traditional worldview of Turkic peoples of South Siberia. Space and time. The material world] (1988) / E. L. L'vova, I. V. Oktiabr'skaia, A. M. Sagalaev and M. S. Usmanova. Novosibirsk, Nauka. 226 p. (In Russ.).

Castells, M. (1996) The rise of the network society. Cambridge, MA, Blackwell. 625 p.

Ethnography and virtual worlds: A handbook of method (2012) / T. Boellstorff, B. Nardi, C. Pearce, T. L. Taylor. Princeton; Oxford, Princeton University Press. 264 p. DOI: https://doi.org/10.2307/j.cttq9s20

Hine, C. (2000) Virtual ethnography. London ; Thousand Oaks ; New Delhi, Sage Publications Ltd. 192 p.

Marcus, G. (2012) Foreword. In: Ethnography and virtual worlds: A handbook of method, by T. Boellstorff, B. Nardi, C. Pearce, T. L. Taylor. Princeton; Oxford, Princeton University Press. Pp. XIII-XX. DOI: https://doi.org/10.2307/j.cttq9s20.4

Markham, A. N. (2013) Fieldwork in social media. What would Malinowski do? Qualitative Communication Research, vol. 2, no. 4, Winter, pp. 434-446. DOI: https://doi.org/10.1525/qcr.2013.2.4.434

Rheingold, H. (1993) The virtual community: Homesteading on the electronic frontier. Reading, MA, Addison-Wesley. 325 p.

Rheingold, H. (2000) The virtual community: Homesteading on the electronic frontier. 2nd ed. Cambridge, MA, MIT Press.

Rheingold, H. (2002) Smart mobs: The next social revolution. Cambridge, MA, Perseus Pub. 296 p.

Submission date: 26.04.2021. 